\title{
The Dilemma and Breakthrough of the Minority Sports Development
}

\author{
Ma Yan \\ Sport \& P.E. College of Shandong Normal University, Jinan, Shandong, 250014
}

\begin{abstract}
By means of literature review, investigation and analysis, the author tried to sum up the dilemmas of minority sports development at present in such aspects as the dispute, exploitation, heritage projects, personnel training, living space, organization and industrial development. Based on the development of national characteristics and national culture, relevant proposals are put forward to help Chinese colorful ethnic culture development better and better.
\end{abstract}

KEYWORDS: ethnic minority; national sports; development dilemma

\section{INTRODUCTION}

China is a multi-ethnic country, consisting of 56 ethnic groups. In this big family, apart from the Han, there are other 55 minority nationalities distributed in different areas. Such multi-ethnic situation provides the basic material for the colorful Chinese civilization. As for sports, there are many excellent sports events of different styles and with the combination of competition and entertainment in ethnic minorities. This provides a multi-level platform for the fitness and entertainment of Chinese people, thus promote national communication and unity. However, with the development of society and globalization, it also brings, in some extent, some limitations, even destructive impact on the development of many excellent Chinese cultures.

\section{OVERVIEW OF MINORITY SPORTS DEVELOPMENT}

China has been doing much work and effort on the exploitation and development of each minority sport. As far as the academic research on minority sports are concerned, China has specially established many research programs including minority sport organization study, development strategy study, event study, project settings, optimization and exploitation and protection research, which played a vital role in the preservation and exploitation of minority sports. As for the organization of minority sports games, since 1953, with the co-sponsorship of the State Ethnic Affairs Commission and the State Sports Committee, the local contractors have held the national traditional minority sports games every four years, which has become a more influential domestic comprehensive one. Nowadays, most provinces and cities have regularly held various forms of minority sports games, which provides authoritative competition platform for the development of minority sports and is of epochmaking significance for the propagation and scientific meaning of the minority sports.

However, with the development of the times, the gradual spread of western cultures and the imperfection of the minority sports development have brought about great impact on the development of minority sports, which not only reflected in the dispute of native and foreign cultures, but also in the self-development of minority sports. These have become the urgent problems for the development of minority sports. Only by solving these problems can enable the sustainable development of minority sports in good order.

\section{THE DILEMMA AND BREAKTHROUGH OF THE DEVELOPMENT OF MINORITY SPORTS}

\subsection{The Collision between the Traditional and the Western and Its Breakthrough}

With the development of the times, the development of globalization integrated human's sharing resources. But, during the communication process of Chinese and Western culture, Chinese national culture has been greatly impacted. Being a developing country, China cannot catch up with developed ones in economy, science and technology. 
Therefore, during cultural import, people incline to be influenced by and adore western culture, which affects greatly the development of Chinese national culture. People tend to sing high praise for Western culture, regard it as fashion indicator, ignore Chinese national culture, and consider our national culture out of time, for example, they think jogging, apparatus exercise, yoga, etc. fashionable, and traditional sports like beanbag game and bamboo jumping out of time, which has great influence on the development of national culture. Nowadays, when world sports integration is speeding up, it is beyond doubt that modern sports shock national sports, especially minority sports. In this situation, we need to strengthen national culture based education, improve the development mode of national culture, and strengthen the heritage and development of national culture, which is fundamentally significant to the healthy sustainable development of fine Chinese national culture, especially minority culture. We must keep the essence of national sports culture and make another integration and innovation on the basis of maintaining our own essence and borrowing the fruits of modern sports, in order to modernize national sports and make it both traditional and modern.

\subsection{The Dilemma of Living Space and Its Breakthrough}

With the development of economy and the progress of science and technology, the attention of people of the 21 st century turned from their national sports to world popular games that had been given more publicity, such as World Cup, the Olympic Games, etc. The weakening and change of people's idea about traditional national culture resulted in the receding tendency of the heritage of national sports culture. Culture however good needs good living space to develop and continue. As far as the development of minority sports is concerned, living space seems especially important. It is a great obstacle for the development of minority culture that minorities are minor in population, the ability of cultural spreading and so on. Part of minority culture, sports culture should be much more emphasized, which can be shown not only in the extent to which people arrange and tap minority sports, but also in all kinds of supporting measures like economic investment, special games, cultivation and placement of related talents, minority sports based programs and so on. The above elements decide the developing direction of the scientization, normalization, specialization and systematization of minority sports; decide the vitality of minority sports; decide the protesting ability of minority sports in the collision between Chinese and western cultures. In planning culture development, this makes it necessary for relevant departments to improve the developing power and space of minority culture, especially minority sports culture, making it grow from multiple dimensions, at different levels, in all aspects and take hold in cultural globalization.

\subsection{The Dilemma of Tapping and Arrangement and Its Breakthrough}

Under the impact of modernization, minority sports appear too weak to protect themselves. Both the death of successors and indifference of the young generation are fatal to them. According to the 2005 sports general investigation by Xinjiang Ethnic Affairs Commission, nearly 40 of traditional Xinjiang games were lost, such as Bharat Festival, bull hooking, JinGeErMan, KongMuBuLake, TaKeTaKe, ErDuoGongChengJi, net casting hunting, Guo, ShaMaErHan, ring hiding, DuGuEr, BuKeSuoKuXiTuLuXi, BaLeWanTaSi, walnut casting, etc.; about 43 games are now under threat, like WoErDaKaMu, Red Stone Game, FeiShenQiLv, BanYao, TiRenBiLi, ErRenFan, QiaKeDuGuLeTuXi. In the similar situation are "SanSheng"of the Yi nationality, male peacock dancing of the Dai nationality, and "Climbing a Ladder of Knives" of the Miao nationality which is handled by only a few wizards and can be seen only in special ceremonies. However, since the government began to play a leading role in protecting traditional culture, a lot of our unknown fine culture has been valued, which is very helpful for protecting national culture. At the same time, many of minority sports games were arranged and tapped systematically and have lasted to this day, which is an impressive feat in the development history of minority sports. In spite of the above achievements, we failed to stop or lower the receding participation of many minority sports games, which shows that we should not only tap and arrange the materials of minority sports, but also implement the improvement and innovation of them on the above basis. There are much more national sports games handed down from Chinese history of more than 5000 years, so we should strive to tap and sort out minority sports, to make those games undiscovered or on the brink of disappearance able to be passed down.

\subsection{The Dilemma and Breakthrough of Training}

Human beings are the carrier of culture, the basic unit of the cultural inheritance, and the power of innovation and development of culture. Schools are the good place and organization to cultivate professional talents; therefore, strengthening the construction of ethnic minority sports professional school to promote the development of ethnic minority sports has fundamental significance. The 
cultivation of the sports specialized talents of ethnic minorities guarantees the development of the sports undertakings of ethnic minorities. In the development of minority sports, all levels of human resources are needed, including scientific researchers, teaching and management staff, organizers, etc. The lack of the talents is the decisive factors in a slow development of ethnic minority sports. But, the talent training has close relationship with social needs. Related job opportunities determine the study direction and the research field. And speaking of the employment system in our country, the post setting of sport talents of ethnic minorities is also relatively ignored. This creates an infinite loop -- less employment, less professional learning; less professional learning, less professionals will there be. It not only plays a promoting role in the cultivation of the professional sports talents of ethnic minorities, but also provides a strong and decisive human basis for the development of ethnic minority sports to improve ethnic minority sports professionals' recruitment, expand the approaches of enrollment and strengthen and optimize the minority sports training professional talents of gradient.

\subsection{The Dilemma and Breakthrough of Organization}

National sports are originated from the life of people of all nationalities, as well as an expression of people's attachment to our national culture and customs. National sports originate among the people and national sports activities exist in people on the basis of the spontaneous organization. National folk sports are entertainment activities that people celebrate the harvest and express their delight and blessing, so they bear their own national character and custom. Although now in many ethnic minority areas, many ethnic sports activities still continue, and minority sports games under the support of all levels of government are in full swing, they lose their original charm and vitality because the participants are economy driven and the events are officially organized. Only by promoting the unofficial organization of ethnic minority sports, encouraging "sports culture autonomy" of minority nationalities and rendering various supports for the development of ethnic minority sports can the excellent culture of the Chinese be inherited generation after generation. Let ethnic stuff return to where it belongs and make it thrive under correct organization and guidance. Only in this way can the national sport become genuine national sport with real national character.

\subsection{The Dilemma and Breakthrough of Industry Development}

Ethnic minority sports are a kind of culture, but, it is more of a kind of resources. With the rapid development of tourism industry and market economy, entertaining spectator sports with ethnic style in the ethnic minority areas are developed and utilized by the investors, and a lot of ethnic minority sports culture brand are created, which is of great significance to the development of ethnic minority sports. it will be difficult for cultural or projects without "self-hematopoietic function" to be inherited and developed. Even the industrialization development of minority sports is gratifying, but, without systematic, scientific planning, making excessive pursuit of economic efficiency will have some impact on minority sports affecting the culture, ecology and social benefits of their region and distort the cultural taste and cultural connotation of national and traditional sports culture. As professor $\mathrm{Xu}$ Hong stated in his paper research on present development situation of "single bamboo drifting" the traditional minority national sports in Guizhou, as regards the development of" single bamboo drifting project, we should research carefully, investigate meticulously and develop rationally, gradually overcome excessive staged authenticity, commercialization and vulgarization. From the point of social benefits, it is the historical and social responsibility for minority sports to be developed to promote the progress of the unity of all nationalities in areas inhabited by minority nationalities and the stability and prosperity of the society. Therefore, in measuring on the benefits of minority national sports development, the relevant departments and organizations should not pay much attention to economic benefits but to the harmonious balance between social benefits, work as strong indicator on the minority sports development, actively promote good development model and means, resist unhealthy practices so that the minority sports and their cultural connotation can be inherited and developed healthily and positively.

\section{CONCLUSION}

We should not only adhere to the principle of national cultural standard, but also ensure that it keeps pace with the time instead of lagging behind for the development of minority sports. The transmission and development of minority national sports must be combined with the characteristics of the times and highlight the characteristics of each ethnic cultural standard and be integrated with the development of modern competitive sports mode to find a more suitable path for the development of ethnic minority sports. Minority national sports are a 
kind of expression of the life and feelings of various ethnic groups and a kind of platform and way of emotional communication. Therefore, for the development of ethnic minority sports we must respect the national culture of intrinsic characteristics and law of development, especially the principal position of national culture and awaken to inherit cultural consciousness to be proud of their outstanding national culture and double treasure and actively participate in the development and prosperity of national culture. At the same time more social force should be absorbed to support the development of minority sports, enabling them to better integrate into the modern people's life.

\section{REFERENCES}

[1] Bai Jin-xiang. 2001. Carrying Forward Chinese Traditional National Sport, Enriching Modern Sports Treasury of the World-A Comment on Study of Traditional National
Sport. Journal of Beijing University of Physical Education. 01(04):5-7.

[2] Chen Zhen-yong. 2001. Analysis and Prospect of the Hot Issues of China's National Minority Sport. Journal of Chendu Sport University. 14(01):24-28.

[3] LiYan-chao \& Yu Zhong-gan. 2010. Scientific Understanding of the Current Development of Minority National Sport. Journal of Physical Education. 1017(2) : 92

[4] Ni Yi-ke. 2004. Consideration on National Traditional Sports Development in Modern China. Science of P.E. 04 (04):74-77.

[5] Rao Yuan \& Zhang Yun-gang. 2003. Analysisof Policy for Minority Sports Industry Development and Social Environment. Journal of Beijing University of Physical Education.03 (04):14-16.

[6] The protection of Intangible Cultural Heritage Convention [EB/OL]. http://www.ihchina.cn/inc/detail.jsp?info_id=50

[7] Zhang Zhi-xin, Pang Hui \& Zang Liu-hong. 2010. Research on Protection of Traditional XinJiang Minority Sport. Journal of Beijing University of Physical Education.10.(3) 